\title{
PATTERNS OF INDUCIBLE PERFUSION DEFECTS BY CARDIAC MRI IN CHRONIC STABLE ANGINA
}

\author{
Manu Manamel ${ }^{1}$, Gomathy Subramaniam², Rajesh G ${ }^{3}$, V. R. Rajendran ${ }^{4}$, Shikha S. Pillai ${ }^{5}$, Anishkumar Nair ${ }^{6}$
}

1 Junior Resident, Department of Radiodiagnosis, Government Medical College, Calicut.

${ }^{2}$ Additional Professor, Department of Radiodiagnosis, Government Medical College, Calicut.

3 Professor, Department of Cardiology, Government Medical College, Calicut.

${ }^{4}$ Professor and Head, Department of Radiodiagnosis, Government Medical College, Calicut

${ }^{5}$ Assistant Professor, Department of Radiodiagnosis, Government Medical College, Calicut.

${ }^{6}$ Senior Resident, Department of Cardiology, Government Medical College, Calicut.

\section{ABSTRACT}

\section{AIMS}

The aims of the study were to assess the prevalence of inducible perfusion defects in patients having chronic stable angina by cardiac MRI stress perfusion study and to assess the patterns of inducible perfusion defect with respect to the arterial territories.

\section{MATERIALS AND METHODS}

The study included 79 subjects who presented at the Cardiology Department of Government Medical College, Calicut, between February 2014 and August 2015 and were diagnosed to have chronic stable angina. The subjects underwent stress CMR using adenosine performed on a 1.5 T MRI scanner. Every subject was meticulously analysed for inducible perfusion defect. If inducible perfusion defect was present, the involved arterial territory and the extent of perfusion defect are assessed using the AHA 17segment model.

\section{RESULTS}

Vast majority (86.1\%) of patients show inducible perfusion defect, while only $13.9 \%$ did not show any ischaemia on administration of adenosine. The most common pattern of involvement of arterial territory is double vessel ischaemia, which is prevalent in $44.12 \%$ of number of patients with inducible ischaemia and $37.97 \%$ of total study population respectively. Combined involvement of LAD and RCA territories is the most common pattern of double vessel ischaemia (21.52\% and $25.0 \%$ respectively). More than one-fourth (27.85\%) of the total study population has inducible ischaemia involving a single arterial territory, out of which Left Anterior Descending (LAD) artery territory was the most common. The least prone artery was LCX. All the three major arterial territories were involved in $12.7 \%$ of total study population and $14.71 \%$ of patients with inducible ischaemia. Almost half the population (49.4\%) has delayed enhancement, which denotes irreversibly scarred myocardium; $24.1 \%$ has viable hibernating myocardium, while $75.9 \%$ did not show any hibernating myocardium; 32 subjects ( $40.51 \%$ of study population) showed inducible ischaemia in addition to delayed enhancement of myocardium.

\section{KEYWORDS}

Cardiac Stress MRI, Chronic Stable Angina, Myocardial Perfusion, Inducible Ischaemia.

HOW TO CITE THIS ARTICLE: Manamel M, Subramaniam G, Rajesh G, et al. Patterns of inducible perfusion defects by cardiac MRI in chronic stable angina. J. Evolution Med. Dent. Sci. 2016;5(60):4211-4216, DOI: 10.14260/jemds/2016/961

\section{INTRODUCTION}

Over the last century, the major causes of death and disability, in the more advanced societies, have shifted from a predominance of nutritional deficiencies and infectious diseases to non-communicable diseases (NCD). Among the NCD, highest mortality is caused by atherosclerotic cardiovascular disease, most frequently ischemic heart disease. There are three major clinical presentations of coronary artery disease: chest pain syndromes, acute coronary syndromes (Including acute myocardial infarction) and sudden death. Chronic stable angina, the initial manifestation of coronary artery disease (CAD) in approximately $50 \%$ of all patients ${ }^{1}$, is usually caused by the obstruction of at least one large epicardial coronary artery by atheromatous plaque.

Financial or Other, Competing Interest: None.

Submission 31-05-2016, Peer Review 14-07-2016,

Acceptance 20-07-2016, Published 28-07-2016.

Corresponding Author:

Manu Manamel,

Manamel House,

SMRA 22, Thattarath Lane,

Palarivattom P.O., Kochi-682025,

Kerala, India.

E-mail: manu.manamel@gmail.com

DOI: $10.14260 /$ jemds $/ 2016 / 961$
Stress testing is one of the most powerful diagnostic approaches to detecting coronary artery disease. These tests are most useful in patients with an intermediate pre-test probability of CAD, because in such patients the results of the stress test whether positive or negative will have the greatest effect on the post-test probability and consequently on clinical management. 'Reversible myocardial ischaemia' refers to improvement in contractile function after coronary revascularization. The decision whether to proceed with the intervention is dependent on the presence and identification of viable myocardium. Patients with dysfunctional but viable myocardium maybe considered for revascularization, whereas patients with irreversibly damaged non-viable myocardium receives no benefit from interventional procedures. MRI can be of great value in decision-making and prognostication in cases of chronic CAD.

\section{AIMS AND OBJECTIVES OF THE STUDY}

- To assess the prevalence of inducible perfusion defects in patients having chronic stable angina by cardiac MRI stress perfusion study.

- To assess the patterns of inducible perfusion defect with respect to the arterial territories. 


\section{METHODS}

Study Design

Cross-sectional study.

\section{Study Setting}

Government Medical College Hospital, Calicut.

\section{Study Period}

Feb 2014 - August 2015

\section{Inclusion Criteria}

More than/equal to 21 yrs. of age. Patients presenting with history of chest pain for $>3$ months.

\section{Exclusion Criteria}

Left Ventricle Ejection Fraction (LVEF) $<35 \%$. History of unprotected left main stenosis $>50 \%$ on prior Coronary Computed Tomography Angiography (CCTA) or prior cardiac catheterization.

Finding of "no obstructive CAD" $(<50 \%$ stenosis in all major epicardial vessels) on prior CCTA or prior catheterization performed within 12 months. Coronary anatomy unsuitable for either PCI or CABG. Acute coronary syndrome within the previous 2 months. PCI within the previous 12 months. Stroke within the previous 6 months or spontaneous intracranial haemorrhage at any time. History of ventricular tachycardia requiring therapy for termination or symptomatic sustained ventricular tachycardia not due to a transient reversible cause. New York Heart Association (NYHA) class III-IV heart failure at entry or hospitalization for exacerbation of chronic heart failure within the previous 6 months.

\section{Sample Size}

Seventy nine patients who presented in the Dept. of Cardiology with chronic stable angina.

\section{Study Methodology}

The patient is subjected to stress CMR using adenosine; $1.5 \mathrm{~T}$ MRI scanner was used for the study. Images were taken after administration of adenosine and after rest. Each case is then meticulously analysed for inducible perfusion defect. If inducible perfusion defect is present, the involved arterial territory and the extent of perfusion defect are assessed. The extent of deficit is analysed using the AHA 17 segment model.

\section{MR Imaging Technique}

2 chamber view, 4 chamber view, short axis view, stress and rest images and delayed images were routinely obtained. Adenosine $140 \mu \mathrm{g} / \mathrm{kg} / \mathrm{min}$ is given as intravenous infusion for 3 mins. to induce relative hyperaemia. This is indicated by a systolic BP fall of $10 \mathrm{mmHg}$ and increase of 10 beats per mins. in the heart rate. By 3 minutes into the infusion, adequate vasodilation should be achieved to allow performing the stress perfusion imaging. The contrast, gadolinium chelate is then injected intravenously as bolus dose into the contralateral vein to adenosine. The dosage used is $0.05 \mathrm{mmol} / \mathrm{kg}$. The patient is then subjected to MRI scan; 3 slices are taken per cycle - at the basal, mid papillary and apical levels of LV. Subsequently, the patient is allowed to rest for 5 mins. during when the physiological parameters comes back to normal. After stabilizing the patient following the stress test, cine CMR can be performed to assess anatomy, ejection fraction and regional wall motion. The same protocol (Excluding the infusion of adenosine) is followed to capture the images while at rest. A rest perfusion study is then performed using identical parameters to the stress test. Finally, delayed enhancement imaging of myocardial infarction can be performed.

\section{Statistical Analysis}

Using Excel 2007 and SPSS 22 statistical software.

An inducible perfusion defect (Inducible ischaemia) manifests itself on the images as hypointense signal in the stress images, but appears normal in rest images. If hypointensity is present on both stress and rest images, the myocardium is in hibernating state. An enhancement which manifests in delayed images (Late gadolinium enhancement) is diagnostic of scarred myocardium.

\section{RESULTS}

\begin{tabular}{|c|c|c|}
\hline Gender & Frequency & Percent \\
\hline Female & 11 & 13.9 \\
\hline Male & 68 & 86.1 \\
\hline Total & $\mathbf{7 9}$ & $\mathbf{1 0 0 . 0}$ \\
\hline Table 1: Gender Distribution of Study Population \\
\hline
\end{tabular}

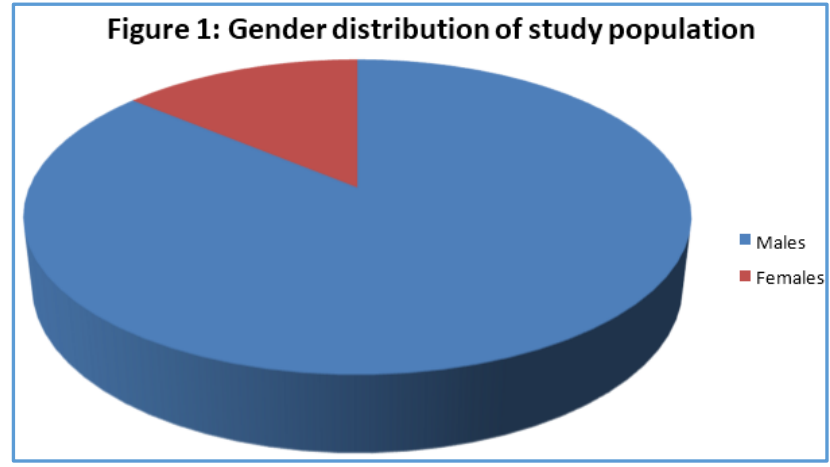

\begin{tabular}{|c|c|c|}
\hline & Frequency & Percentage \\
\hline $35-50$ & 22 & $27.8 \%$ \\
\hline $51-65$ & 41 & $51.9 \%$ \\
\hline $66-80$ & 16 & $20.3 \%$ \\
\hline \multicolumn{2}{|c|}{ Table 2: Age Distribution of Study Population } \\
\hline
\end{tabular}

Figure 2: Age distribution of subjects (in years)

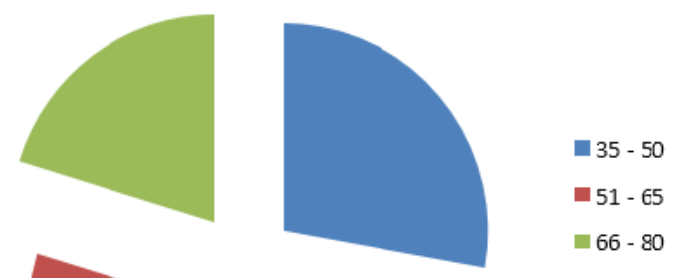

\begin{tabular}{|c|c|c|}
\hline $\begin{array}{c}\text { Inducible } \\
\text { Perfusion Defect }\end{array}$ & Frequency & $\begin{array}{c}\text { Percentage } \\
\text { (\%) }\end{array}$ \\
\hline Yes & 68 & 86.1 \\
\hline No & 11 & 13.9 \\
\hline Total & $\mathbf{7 9}$ & $\mathbf{1 0 0}$ \\
\hline Table 3: Frequency of Inducible Perfusion Defect \\
\hline
\end{tabular}




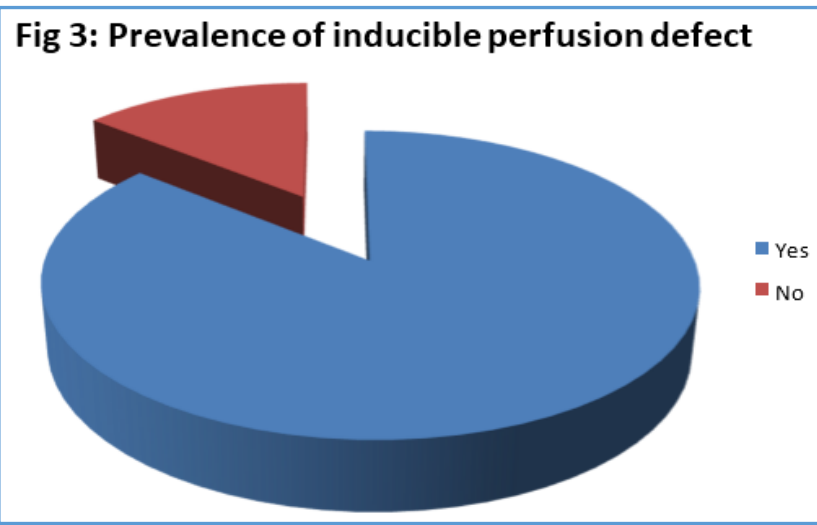

\begin{tabular}{|c|c|c|}
\hline Cardiac Segment & Frequency & Percentage (\%) \\
\hline Basal Anterior & 14 & 17.7 \\
\hline Basal Anteroseptal & 46 & 58.2 \\
\hline Basal Inferior & 13 & 16.5 \\
\hline Basal Inferoseptal & 37 & 46.9 \\
\hline Basal Inferolateral & 16 & 20.3 \\
\hline Basal Anterolateral & 21 & 26.6 \\
\hline Mid Anterior & 12 & 15.2 \\
\hline Mid Anteroseptal & 46 & 58.2 \\
\hline Mid Inferoseptal & 41 & 51.9 \\
\hline Mid Inferior & 10 & 12.7 \\
\hline Mid Inferolateral & 14 & 17.8 \\
\hline Mid Anterolateral & 16 & 20.3 \\
\hline Apical Anterior & 22 & 27.9 \\
\hline Apical Septal & 41 & 51.9 \\
\hline Apical Inferior & 17 & 21.5 \\
\hline Apical Lateral & 10 & 12.6 \\
\hline \multicolumn{2}{|c|}{ Table 4: Frequency of Involvement } \\
of Each Cardiac Segment \\
\hline \multicolumn{2}{|c|}{}
\end{tabular}

\begin{tabular}{|c|c|c|}
\hline $\begin{array}{c}\text { Number of } \\
\text { Segments }\end{array}$ & Frequency & Percentage (\%) \\
\hline 0 & 11 & 13.9 \\
\hline 1 & 0 & 0 \\
\hline 2 & 5 & 6.3 \\
\hline 3 & 5 & 6.3 \\
\hline 4 & 13 & 16.5 \\
\hline 5 & 14 & 17.7 \\
\hline 6 & 11 & 13.9 \\
\hline 7 & 9 & 11.4 \\
\hline 8 & 6 & 7.6 \\
\hline 9 & 0 & 0 \\
\hline 10 & 3 & 3.8 \\
\hline 11 & 2 & 2.5 \\
\hline 12 & 0 & 0 \\
\hline \multicolumn{2}{|c|}{ Table 5: Frequency of Total Number of Segments } \\
\hline \multicolumn{2}{|c|}{} \\
\hline
\end{tabular}

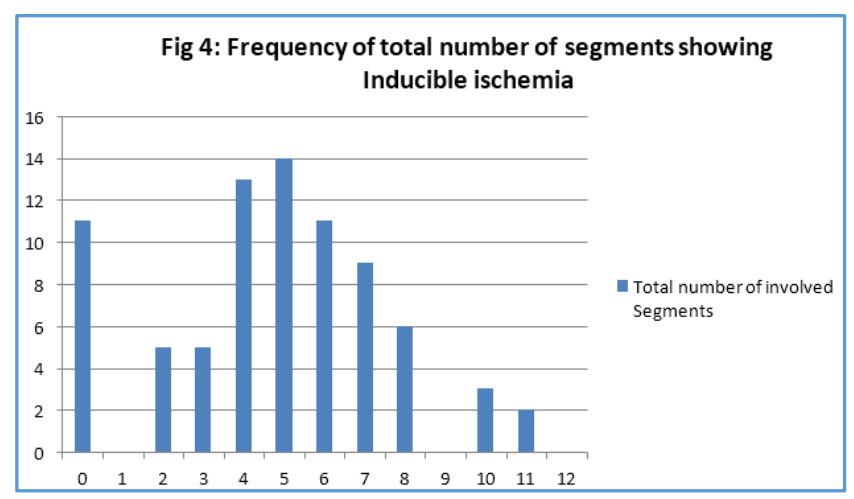

\begin{tabular}{|c|c|c|}
\hline $\begin{array}{c}\text { Late Gadolinium } \\
\text { Enhancement }\end{array}$ & Frequency & $\begin{array}{c}\text { Percentage } \\
\text { (\%) }\end{array}$ \\
\hline Yes & 39 & 49.4 \\
\hline No & 40 & 50.6 \\
\hline \multicolumn{2}{|c|}{ Table 6: Frequency of Late } \\
Gadolinium Enhancement (LGE) \\
\hline
\end{tabular}

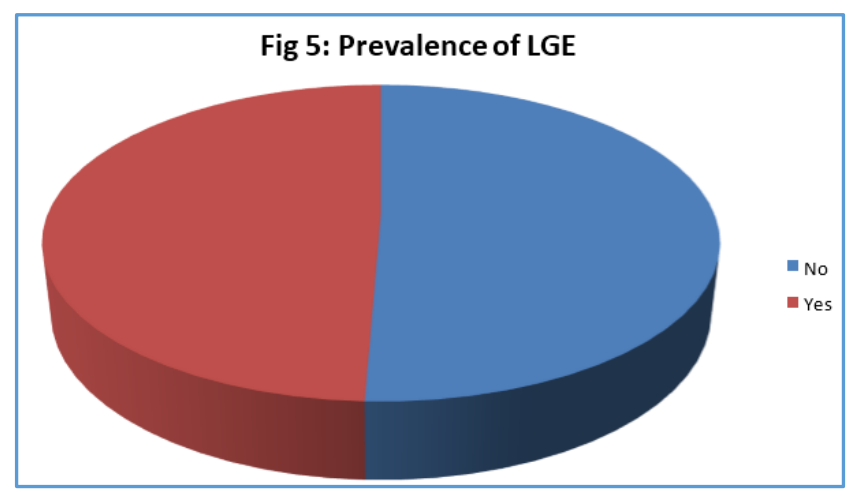

\begin{tabular}{|c|c|c|c|c|}
\hline & \multicolumn{2}{|c|}{$\begin{array}{c}\text { Delayed } \\
\text { Enhancement }\end{array}$} & \multirow[b]{2}{*}{ Total } \\
\hline & & Present & Absent & \\
\hline \multirow{3}{*}{ 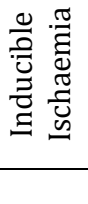 } & Present & 32 & 36 & 68 \\
\hline & Absent & 7 & 4 & 11 \\
\hline & Total & 39 & 40 & 73 \\
\hline
\end{tabular}

\begin{tabular}{|c|c|c|}
\hline $\begin{array}{c}\text { Hibernating } \\
\text { Myocardium }\end{array}$ & Frequency & $\begin{array}{c}\text { Percentage } \\
\text { (\%) }\end{array}$ \\
\hline Yes & 19 & 24.1 \\
\hline No & 60 & 75.9 \\
\hline Total & $\mathbf{7 9}$ & $\mathbf{1 0 0}$ \\
\hline Table 8: Frequency of Hibernating Myocardium \\
\hline
\end{tabular}

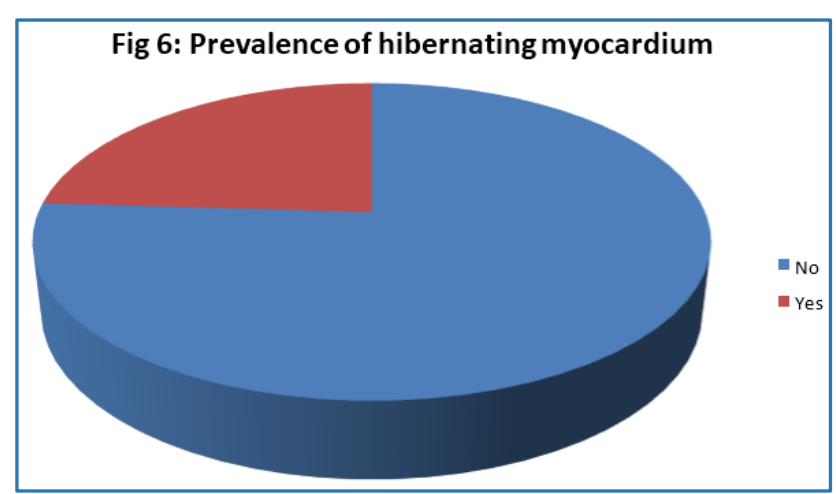

\begin{tabular}{|c|c|c|c|}
\hline $\begin{array}{c}\text { No. of } \\
\text { Vessels }\end{array}$ & Frequency & $\begin{array}{c}\text { \% of Study } \\
\text { Population }\end{array}$ & $\begin{array}{c}\text { \% of Number of } \\
\text { Patients with } \\
\text { Inducible } \\
\text { Ischaemia }\end{array}$ \\
\hline $\begin{array}{c}\text { Single } \\
\text { Vessel }\end{array}$ & 22 & $27.85 \%$ & $32.36 \%$ \\
\hline $\begin{array}{c}\text { Double } \\
\text { Vessel }\end{array}$ & 30 & $37.97 \%$ & $44.12 \%$ \\
\hline $\begin{array}{c}\text { Triple } \\
\text { Vessel }\end{array}$ & 16 & $20.25 \%$ & $23.53 \%$ \\
\hline \multicolumn{2}{|r|}{ Table 9: Distribution of Arterial Territories } \\
Involved in Inducible Ischaemia
\end{tabular}




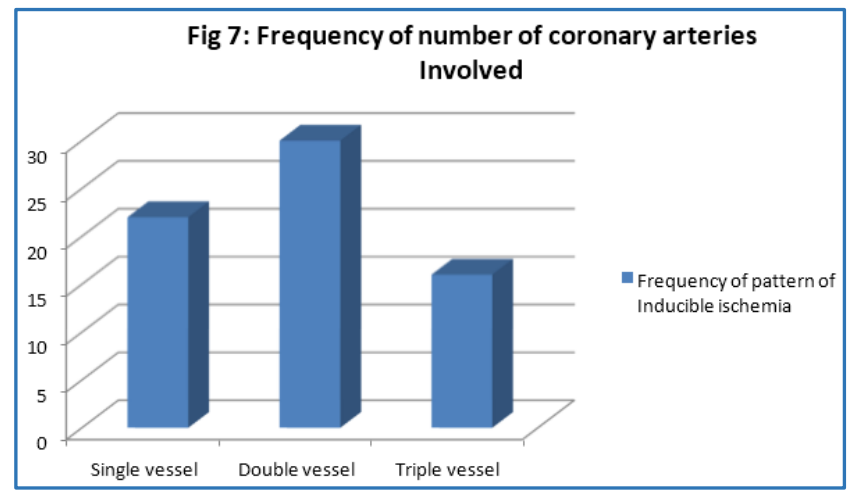

\begin{tabular}{|c|c|c|c|}
\hline $\begin{array}{c}\text { Arterial } \\
\text { Territory }\end{array}$ & Number & $\begin{array}{c}\text { \% of Patients } \\
\text { with } \\
\text { Inducible } \\
\text { Ischaemia }\end{array}$ & $\begin{array}{c}\text { \% of } \\
\text { Study } \\
\text { Population }\end{array}$ \\
\hline LAD & 10 & $14.71 \%$ & $12.7 \%$ \\
\hline LCX & 4 & $5.88 \%$ & $5.1 \%$ \\
\hline RCA & 8 & $11.76 \%$ & $10.1 \%$ \\
\hline Total & $\mathbf{2 2}$ & $\mathbf{3 2 . 3 6 \%}$ & $\mathbf{2 7 . 8 5 \%}$ \\
\hline \multicolumn{4}{|c|}{ Table 10: Patterns of } \\
Single Vessel Disease \\
\hline
\end{tabular}

\begin{tabular}{|c|c|c|c|}
\hline Artery & Frequency & $\begin{array}{c}\text { \% of Study } \\
\text { Population }\end{array}$ & $\begin{array}{c}\text { \% of Patients } \\
\text { with Inducible } \\
\text { Ischaemia }\end{array}$ \\
\hline $\begin{array}{c}\text { LAD+ } \\
\text { LCX }\end{array}$ & 8 & $10.13 \%$ & $11.76 \%$ \\
\hline $\begin{array}{c}\text { LAD + } \\
\text { RCA }\end{array}$ & 17 & $21.52 \%$ & $25 \%$ \\
\hline $\begin{array}{c}\text { LCX + } \\
\text { RCA }\end{array}$ & 5 & $6.33 \%$ & $7.35 \%$ \\
\hline Total & 30 & 37.97 & $\mathbf{4 4 . 1 2 \%}$ \\
\hline \multicolumn{4}{|c|}{ Table 11: Patterns of Double Vessel Disease } \\
\hline
\end{tabular}

\begin{tabular}{|c|c|c|c|}
\hline Artery & Frequency & $\begin{array}{c}\% \text { of } \\
\text { Total } \\
\text { Number }\end{array}$ & $\begin{array}{c}\% \text { of Patients } \\
\text { with } \\
\text { Inducible } \\
\text { Ischaemia }\end{array}$ \\
\hline $\begin{array}{c}\text { LAD+ LCX + } \\
\text { RCA }\end{array}$ & 10 & $12.7 \%$ & $14.71 \%$ \\
\hline \multicolumn{2}{|c|}{ Table 12: Frequency of Triple Vessel Ischaemia } \\
\hline
\end{tabular}

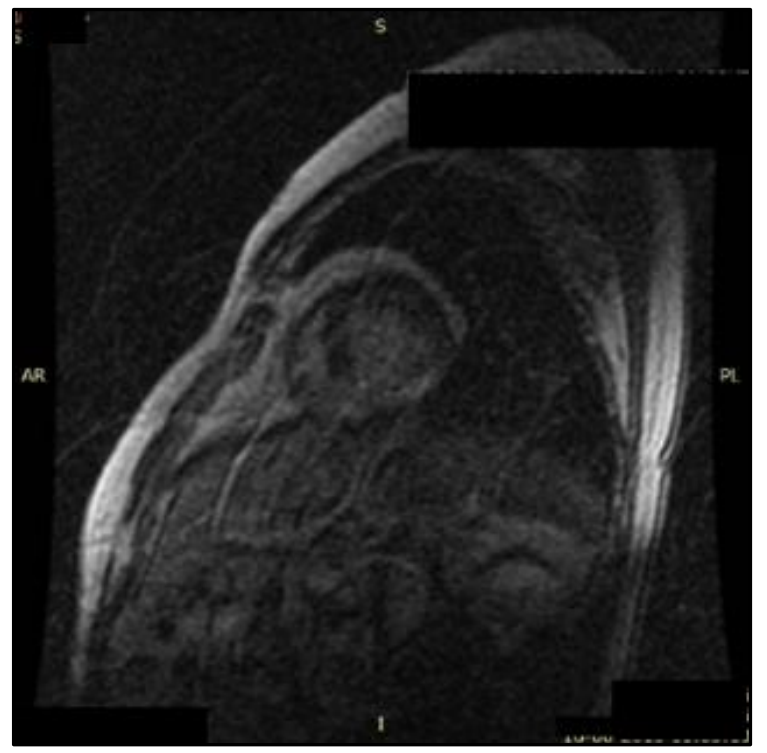

Fig. 1: Late Gadolinium Enhancement. Hyperintensity of Inferolateral, Inferior and Inferoseptal Myocardium in Delayed Images

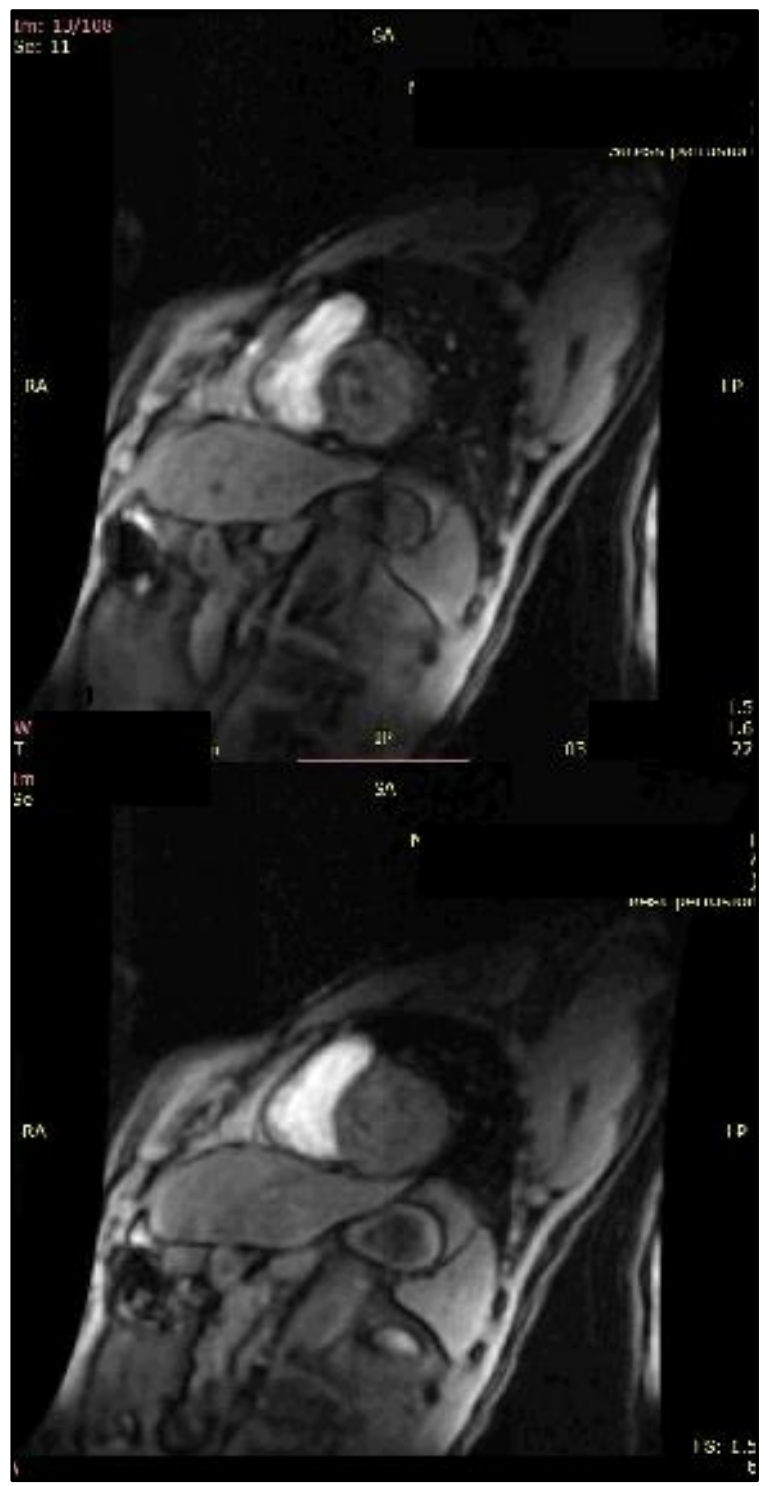

Fig. 2: Inducible Ischaemia of Basal Segments. Hypointensity of Inferoseptal and Anteroseptal Myocardium in Stress Images But Not Rest Images 


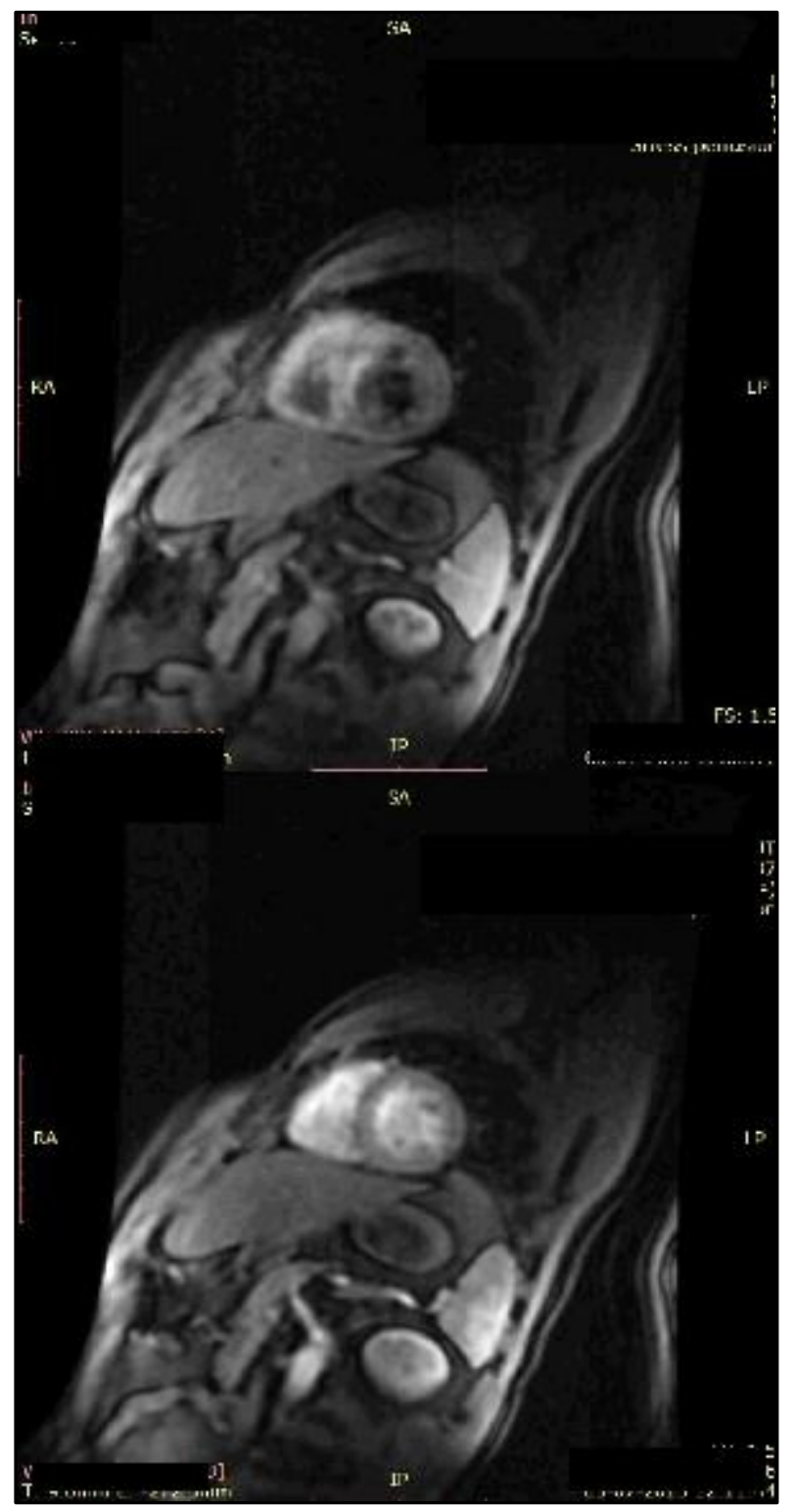

Fig. 3: Inducible Ischaemia of Mid Segments. Hypointensity of Inferoseptal, Anteroseptal and Anterior Myocardium in Stress Images But Not Rest Images

\section{DISCUSSION}

In the present study, a total of seventy nine patients who were diagnosed as cases of chronic stable angina underwent cardiac stress MRI evaluation. The visual interpretation of perfusion images was performed using the standard 17-segment model as recommended by the American Heart Association.

In the present study, the most common age group to which the subjects belong to is 50 to 65 years. According to Diamond $\mathrm{G} A$ et $\mathrm{al}^{2}$, the pre-test likelihood of coronary artery disease increases with each ongoing decade. However, in our study, the prevalence was highest in the middle aged group and declined in the highest age group probably because of the stringent inclusion and exclusion criteria. The subjects who were already diagnosed in the immediate past are excluded from the study.

In the present study, almost half of the study population showed Late Gadolinium Enhancement (LGE) denoting irreversibly scarred myocardium. In the previously conducted

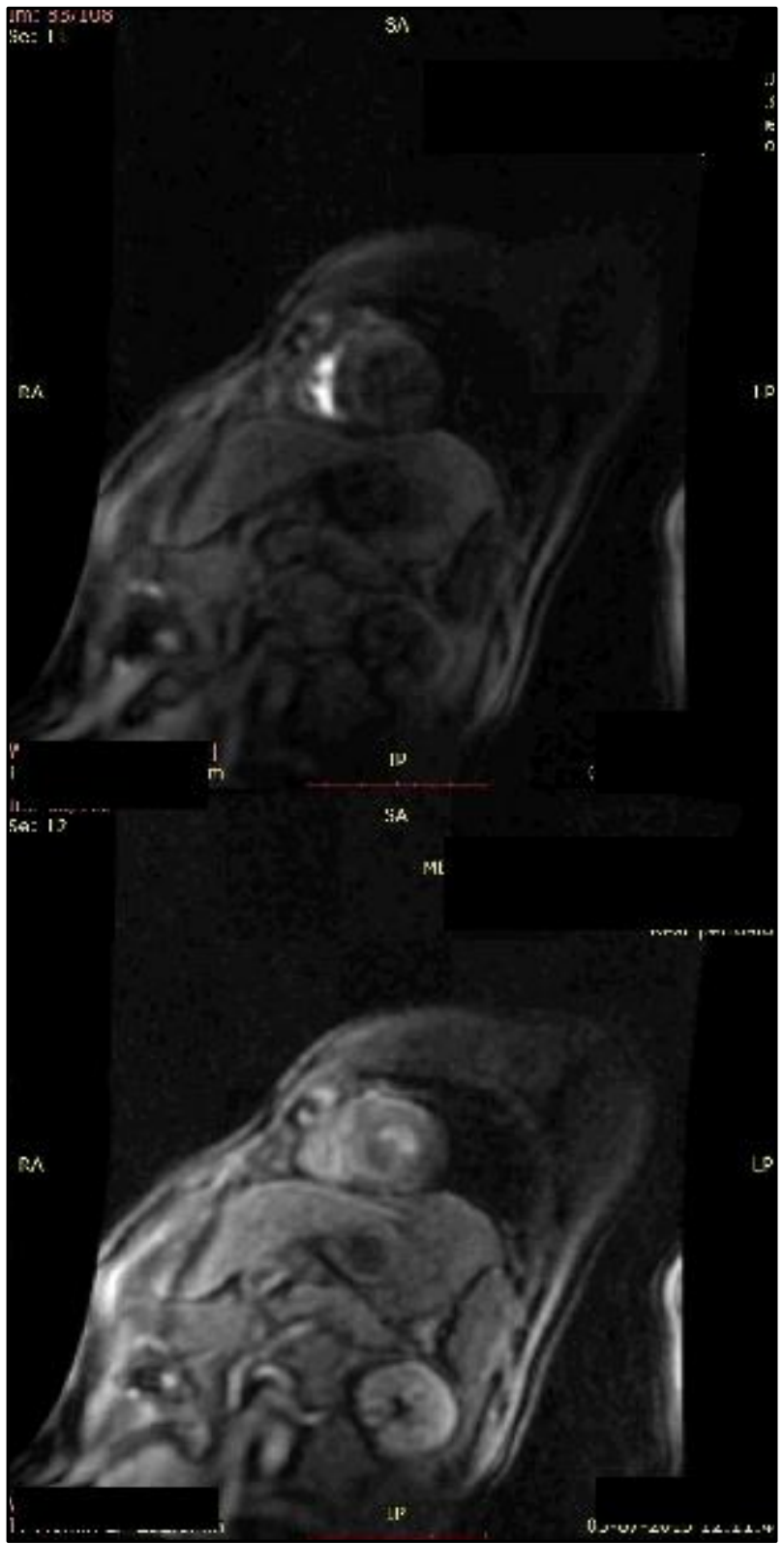

Fig. 4: Inducible Ischaemia of Apical Segment. Hypointensity of Septal Myocardium in Stress Images But Not Rest Images

studies, LGE has been reported to be present in $23 \%$ of patients who present with signs and symptoms of CAD and in about $20 \%$ of randomly selected patients aged at least 70 years. In the study conducted by Breuckmann $\mathrm{F}^{\text {t }} \mathrm{al}^{3}$, there was Late Gadolinium Enhancement (LGE) in normal asymptomatic marathon runners. Unexpectedly, high incidence of LGE was related to the strenuous routine exercise of marathon runners. A high incidence of LGE in the present study could be due to the inherent property of the study group, which comprised patients only from Department of Cardiology at a tertiary referral centre. Routine CAD cases present at the Department of Internal Medicine, who in turn refer the refractory and intractable cases to the Department of Cardiology.

In the present study vast majority $(86.1 \%)$ of patients show inducible perfusion defect, while only $13.9 \%$ did not show any perfusion defect on administration of adenosine. According to Gehi and Co-workers. ${ }^{4} 24 \%$ of outpatients with 
stable CHD have inducible ischaemia by exercise stress echocardiography and $80 \%$ of patients with inducible ischaemia did not report significant symptoms of angina. Fleg et $\mathrm{al}^{5}$ found the prevalence of ischaemia by stress thallium perfusion imaging to be $<5 \%$ in apparently healthy individuals 40 to 60 years of age in the Baltimore Longitudinal Study of Aging (BLSA). Since the present study population comprised only symptomatic patients from a tertiary referral centre, the incidence is expected to be higher.

In the present study, 32 cases $(40.51 \%$ of study population) showed LGE and inducible ischaemia, but not necessarily in the same arterial territories. This group was the most vulnerable for myocardial injury among the study population. The LGE images suggest that these subjects have non-viable myocardium, which developed following a previous silent or overt vascular event. Inducible ischaemia represented that tissue which is prone for injury but is salvageable. Absence of LGE correlates with measures of viability irrespective of resting function. Selvanayagam JB et $\mathrm{al}^{6}$ proved that the likelihood of improvement in regional contractility after revascularization is inversely related to the transmural extent of LGE.

The most commonly involved cardiac segments in the present study was mid-anteroseptal and basal anteroseptal segments. These segments are involved in $58.2 \%$ of the study population. Both these segments are supplied by the LAD artery, which is the most commonly involved artery in CAD. Basal segment is involved in a more proximal stenosis of the LAD, while distal stenosis would spare the basal segment.

The most common pattern of involvement of arterial territory in the present study is double vessel ischaemia, which is prevalent in $44.12 \%$ of number of patients with inducible ischaemia and $37.97 \%$ of total study population respectively. This was in contradiction to Burggraf and coworkers. ${ }^{7}$ who observed single vessel disease to be the most common pattern. Variation of the territorial supply of epicardial arteries could have confounded the analysis in the present study.

Combined involvement of LAD and RCA territories is the most common pattern of double vessel ischaemia in the present study. This is similar to the study conducted by Burggraf and co-workers. ${ }^{7}$ which states that the most common pattern among double vessel disease is LAD and RCA involvement.

More than one-fourth $(27.85 \%)$ of the total population in the present study has inducible ischaemia involving a single arterial territory, out of which Left Anterior Descending (LAD) artery territory was the most common. In the study conducted by Demer et $\mathrm{al}^{8}$, it was seen that LAD is the most commonly involved artery in CAD.

All the three major arterial territories were involved in $12.71 \%$ of total study population, which was $14.71 \%$ of patients showing inducible ischaemia. This prevalence was less than what was observed by Burggraf and co-workers. ${ }^{7}$, where $25 \%$ of the morbid population had triple vessel disease.
The presence and the severity of inducible ischaemia at the time of screening are strongly and independently associated with long-term prognosis and the development of ACS.

All the studies that have been enumerated converge on the fact that presence of inducible ischaemia on stress testing markedly accentuates the probability of having a cardiac complication. Therefore, the study subject has to be put under strict preventive measures against the adverse event.

\section{CONCLUSIONS}

1. Stress MRI is a valuable tool in determining the course of management.

2. A vast majority of patients (86.1\%) with chronic stable angina had inducible ischaemia suggestive of viable but ischaemic myocardium.

3. The most frequent pattern of coronary artery involvement was double vessel disease, out of which LAD and RCA was most frequently involved. The second most common was single vessel pattern. Triple vessel disease was the least common.

4. Almost half (49.4\%) of the study population had areas of scarred myocardium, which could not be revived.

\section{REFERENCES}

1. Kannel WB, Feinleib M. Natural history of angina pectoris in the Framingham study: prognosis and survival. Am J Cardiol 1972;29(2):154-63.

2. Diamond GA, Forester JS. Analysis of probability as an aid in the clinical diagnosis of coronary-artery disease. $\mathrm{N}$ Engl J Med 1979;300(24):1350-8.

3. Breuckmann F, Mohlenkamp S, Nassenstein $\mathrm{K}$, et al. Myocardial late gadolinium enhancement: prevalence, pattern, and prognostic relevance in marathon runners. Radiology 2009;251(1):50-7.

4. Gehi AK, Rumsfeld JS, Liu H, et al. Relation of selfreported angina pectoris to inducible myocardial ischemia in patients with known coronary artery disease: the heart and soul study. Am J Cardiol 2003;92 (6):705-7.

5. Fleg JL, Gerstenblith G, Zonderman AB, et al. Prevalence and prognostic significance of exercise-induced silent myocardial ischemia detected by thallium scintigraphy and electrocardiography in asymptomatic volunteers. Circulation 1990;81(2):428-36.

6. Selvanayagam JB, Kardos A, Francis JM, et al. Value of delayed-enhancement cardiovascular magnetic resonance imaging in predicting myocardial viability after surgical revascularization. Circulation 2004;110 (12):1535-41.

7. Burggraf GW, Parker JO. Prognosis in coronary artery disease. Angiographic, hemodynamic, and clinical factors. Circulation 1975;51(1):146-56.

8. Demer LL, Gould KL, Goldstein RA, et al. Assessment of coronary artery disease severity by positron emission tomography. Comparison with quantitative arteriography in 193 patients. Circulation 1989;79(4): 825-35. 